\section{The anterior all-ceramic crown: a rationale for the choice of ceramic and cement}

\author{
B. Mizrahi ${ }^{1}$
}

VERIFIABLE CPD PAPER

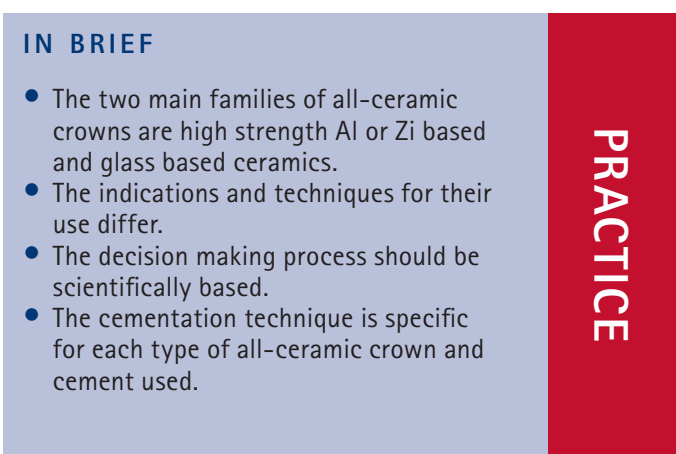

\begin{abstract}
The full coverage, all-ceramic restoration of an anterior tooth is a challenging clinical situation for which a variety of allceramic systems and cements are available. The decision making process involves the consideration of a number of factors such as underlying substrate colour, tooth preparation geometry, margin location and cementation system. This article discusses the rationale behind these factors and presents a logical and scientific based sequence for the decision making process. A clinical case is presented to demonstrate the requirements and materials necessary for the optimal resin bonded anterior crown.
\end{abstract}

\section{INTRODUCTION}

The crowning of anterior teeth incisors is a demanding procedure. The patient's aesthetic expectations are usually high and the final result is largely dependent on the skill of the dental technician. It has been shown that in the hands of the average dental technician, all-ceramic systems exhibit potential for more shade matches than metal ceramic systems. ${ }^{1}$ It is thus not surprising that all-ceramic crowns on anterior teeth are growing in popularity.

Although traditional metal-ceramic systems may not perform as well aesthetically, they nevertheless do have biomechanical advantages and should be considered in situations where aesthetics is not the major driving factor. Their advantages include:

- Proven clinical track record

- Ability to vary marginal configuration and material depending on the dentist's preference and the biomechanical

Specialist in Prosthodontics and Restorative Dentistry, Clinical Lecturer, Eastman Dental Institute/Fellow, American College of Prosthodontists; practising at 39 Harley Street, London, W1G $80 \mathrm{H}$

Correspondence to: Dr Basil Mizrahi

Email: info@basilmizrahi.co.uk

\section{Refereed Paper}

Accepted 11 June 2008

DOI: $10.1038 /$ sj.bdj.2008.735

${ }^{\circledR}$ British Dental Journal 2008; 205: 251-255 situation (eg metal bevel, porcelain shoulder, metal palatal surface)

- Ability to splint adjacent crowns

- The thickness of the metal coping can be varied whereas ceramic performs better with a uniform thickness

- Because of the inherent limitations and dimensions of milling systems, cast metal produces a more precise internal fit than milled all-ceramic crowns. ${ }^{2,3}$ This in turn allows for better resistance form to be incorporated into the tooth preparation

- Metal is better able to withstand higher stress concentrations from more abrupt line angles in the tooth preparation. This, once again, leads to the ability to incorporate more resistance form into the tooth preparation.

Once the decision has been made to use an all-ceramic system, the dentist then needs to decide which system to use. There is currently no evidence to support the universal application of a single all-ceramic system for all clinical situations. $^{3}$

There are two basic families of allceramic systems to choose from:

1. Low strength, etchable, glass based ceramics. Examples of these include:

- IPS Empress and IPS emax (Ivoclar Vivadent, Lichtenstein)

- Authentic (Jensen, CT, USA)
- Finesse (DENTSPlY Ceramco, PA, USA)

- Traditional feldspathic porcelain

2. High strength, non-etchable, alumina (Al) or zirconia (Zi) based ceramics. Examples of these include:

- Procera (NobelBiocare, Sweden)

- Lava (3M ESPE, Minn, USA)

- In-Ceram (Vita, Germany)

- Zircon (DCS, Switzerland)

In general, the alumina or zirconia based ceramics have better mechanical properties, but the glass based ceramics have better optical properties. ${ }^{4}$ Both systems when used with the correct indications and techniques perform well. ${ }^{5-8}$

Correct decision making as to which all-ceramic system to use requires consideration of two main factors:

1. Underlying tooth/substrate colour

2. The cementation system to be used which in turn is based on:

i) resistance form of the tooth preparation

ii) margin location of the tooth preparation.

\section{UNDERLYING TOOTH/ SUBSTRATE COLOUR}

Glass based all-ceramic crowns are more translucent than their alumina or zirconia counterparts and it has been shown 
that they need up to $2 \mathrm{~mm}$ of porcelain to block out dark underlying colour. ${ }^{9} 10$ For this reason, glass based, all-ceramic systems should not be used on dark underlying surfaces. The temporary crown is a useful guide and if its shade is influenced by the underlying substrate, an $\mathrm{Al}$ or $\mathrm{Zi}$ based crown system should be used.

If aesthetics is not a key driving factor in the treatment, this factor can be bypassed in favour of a decision based on choice of cementation systems.

\section{CEMENTATION SYSTEMS}

Full coverage crowns can be retained either by conventional luting cements or by resin cements. Glass based, low strength crowns need to be bonded into place with a resin cement in order to achieve clinically acceptable strength levels. $\mathrm{Al}$ or $\mathrm{Zi}$ based high strength crowns have adequate independent strength and can be cemented with either a conventional luting cement or a resin cement.

If a resin cement is not to be used, a resin modified glass ionomer (rmgi) is the conventional luting cement of choice. Glass-ionomer is still considered the only material that self-adheres to tooth tissue and this may be beneficial in terms of resistance to hydrolytic degradation. ${ }^{11}$ There have been studies to show that despite initial concerns regarding excessive expansion, use of these cements under high strength, allceramic crowns is not problematic. ${ }^{12,13}$ In a study carried out by Blatz et al. ${ }^{14}$ although the rmgi cement had a low bond strength to zirconia, it was less affected by in vitro ageing compared to resin cements.

The concern that rmgi cements are not translucent and will affect the colour of the overlying crown has been shown to be unfounded. Vichi et al. showed they have no clinical significant effect on colour when used under $\mathrm{Al}$ or $\mathrm{Zi}$ based crowns. ${ }^{10}$

A possible additional advantage of these rmgi cements is their potential fluoride release and antimicrobial effect which has been shown to be significantly greater than resin cements. ${ }^{15}$

The decision regarding what cementation system to use should be made prior to deciding what crown system to use and is
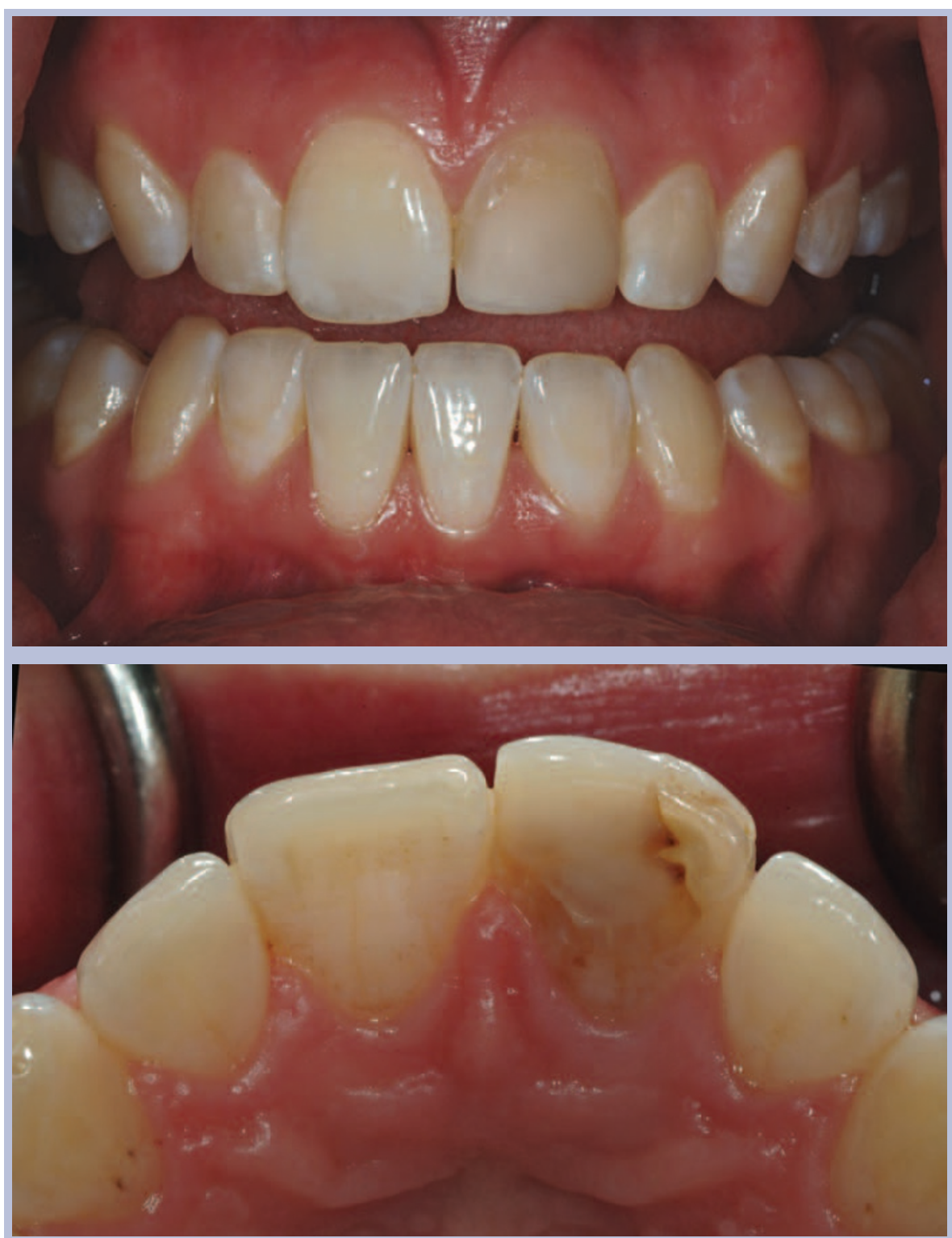

Figs 1-2 Pre-op views of discoloured composite restoration on endodontically treated tooth 21. Note the entire palatal surface formed from a composite resin restoration

based on the resistance form and margin location of the tooth preparation.

\section{i) Resistance form}

Resistance form is the dominant factor to consider when deciding what cement system to use. Resistance form prevents rotation of the crown around a fixed point and resists its dislodgement along an axis other than path of placement. It is a physical phenomenon dependent on the geometry of the tooth preparation and the precision of the crown fit, both of which generally remain unchanged over time. Retention is the resistance to dislodgement of the crown in a vertical direction. It is a chemical phenomenon dependent on the strength of the cement which is subject to degradation/weakening over time.

Resistance form has traditionally been seen as being the most important factor for long term success of a crown. ${ }^{16}$ In a study by Trier et al., ${ }^{17}$ 95\% of crowns that became uncemented lacked resistance form. The problem with resistance is that it is achieved at the expense of tooth structure. Where it is lacking or would be too destructive to enhance, modern resin cements with their high retentive bond strengths may compensate for this.

In summary, if the tooth preparation lacks adequate resistance form (tapered or short preparations), a resin cement should be used. If there is adequate resistance form, the decision is then based on margin location. 


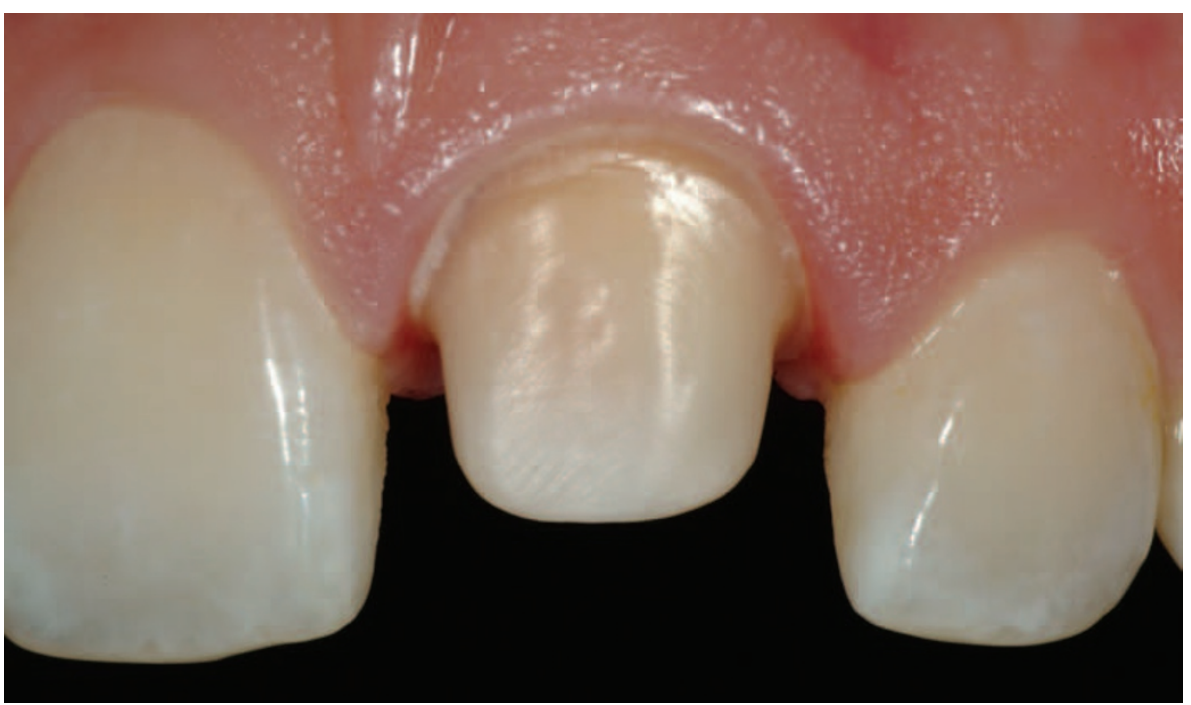

Fig. 3 Tooth preparation with equigingival margins in enamel. Note smooth preparation with no sharp angles

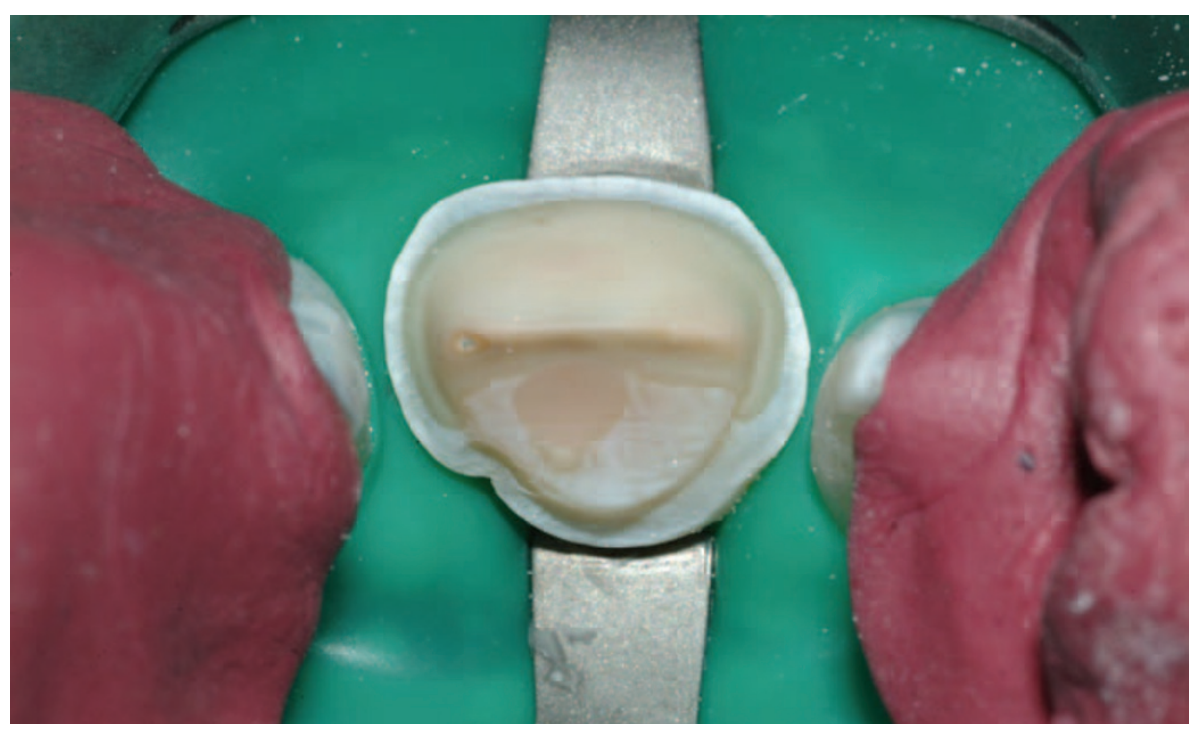

Fig. 5 Rubber dam applied to tooth. Note exposure of all enamel margins and optimal moisture control

\section{ii) Margin location}

The margins of anterior crowns are often placed beneath the free gingival margin for some of the following reasons: ${ }^{18,19}$

- The presence of existing restorations, caries, erosion lesions

- To produce a cervical crown ferrule on endodontically treated teeth

- To improve the aesthetics of discoloured teeth

- To hide the marginal junction between crown and tooth.

Using resins cements on dentine or cementum margins is fraught with potential problems and the dentist is often left with a clinical dilemma of whether to use a resin or an rmgi cement. Resin cements are highly technique

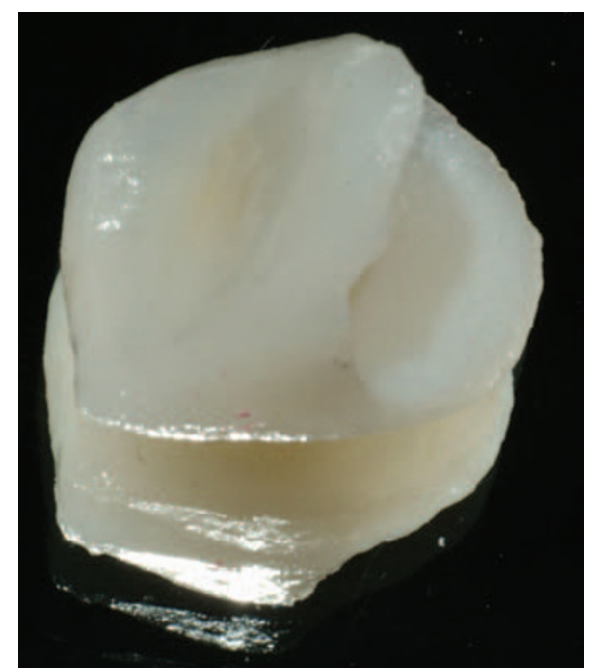

Fig. 4 Definitive all-ceramic crown (Empress Esthetic). Note the thin margins with translucent porcelain

significant loss of adhesion when resin cements are used ${ }^{22}$ and there is a greater possibility of microleakage. ${ }^{23-26}$ Ferrari et al. ${ }^{27}$ showed that the cervical margins of single-unit all-porcelain crowns must be considered as one of the weakest areas of this type of aesthetic restoration.

Another problem with resin cementation on subgingival margins is moisture control. Optimal moisture control is obtained with rubber dam application which is usually not possible to use on subgingival margins. If moisture control is inadequate, the entire bonding procedure may be compromised and a cement with reduced moisture sensitivity such as an rmgi should be considered. ${ }^{28,29}$

\section{THE OPTIMAL RESIN BONDED ANTERIOR CROWN}

sensitive and although they are heavily promoted by the trade industry, they have a limited clinical track record. While laboratory studies are important and often show good results, these may not be directly extrapolated to in vivo conditions. $^{20}$ There is also evidence to show that traditional zinc phosphate cement, although successful under well fitting metal margins, does not perform equally well under all-ceramic crowns. ${ }^{21}$ The myriad of conflicting information available in the scientific literature illustrates that the resin bonding technology is still developing. Hopefully, with time and ongoing research, the decision making process will become clearer.

Finish lines placed beyond the cemento-enamel junction result in a
The most difficult area to create matching aesthetics is the cervical margin where there is a transition from tooth surface to crown. In this area because of the narrowing of the tooth and pulp proximity, space for restorative material is minimal. If the underlying tooth colour is not overly dark and the preparation margins are on enamel, a glass based, all-ceramic crown can be made with margins similar to that for a porcelain veneer $(0.5 \mathrm{~mm})$. Although extremely fragile off the tooth, these margins become strengthened by resin cementation onto the underlying tooth enamel.

Teeth being crowned usually have previous crowns or large restorations on them and the remainder of the crown 


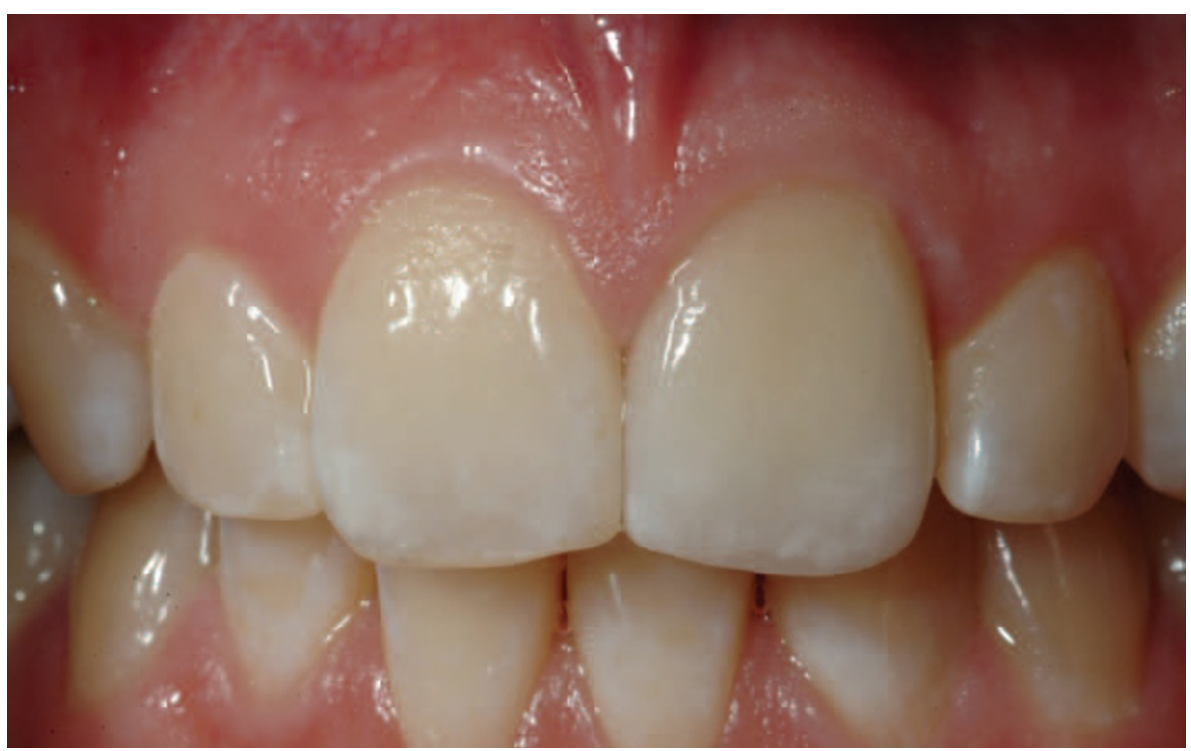

Fig. 6 Final restoration after six months showing excellent cervical aesthetics with invisible equigingival margins

preparation is generally more aggressive and into dentine ( $1.2 \mathrm{~mm}$ labially and $\sim 2 \mathrm{~mm}$ incisally). This also allows for adequate porcelain thickness to provide increased strength and to develop the necessary aesthetics (Figs 1-4). The concept of a dentine bonded crown has been discussed by Burke et al. as arguably an ideal restoration..$^{30,31}$ It differs from that of a $360^{\circ}$ porcelain veneer where the tooth is previously unrestored and all attempts are made to remain in enamel.

The equigingival margins allow for placement of rubber dam for optimal moisture control during the resin bonding procedure (Fig. 5). Bonding to the marginal enamel provides a good seal that protects the more vulnerable underlying resin-dentine bond against degradation through water exposure. ${ }^{32}$ An indiscernible equigingival margin can then be obtained by use of translucent marginal porcelain together with a translucent resin cement thereby taking advantage of the 'contact lens effect' as described by Materdomini et al. (Fig. 6). ${ }^{33}$ Such invisible equigingival margins are not possible with alumina or zirconia based systems because of their increased opacity which requires their margins to be hidden subgingivally.

Another advantage of this type of 'invisible margin crown' is that future gingival recession will not cause unsightly exposure of crown margins.

In summary, the requirements for the optimal resin bonded anterior crown are:
- A good underlying substrate colour

- Tooth preparation margins on enamel for predictable resin bonding

- Ability to place rubber dam for optimal moisture control during bonding

- A glass based all-ceramic system for optimal translucency

- A resin cement for optimal strength and adhesion/sealing.

\section{DISCUSSION}

Modern dentistry has seen the development of many new materials and techniques. Two major developments in recent times are dentine bonding and stronger all-ceramic crown systems. These technologies are still relatively new and therefore have not stood the test of time; good unequivocal scientific evidence is sparse. The dentist is left with the uneasy predicament of trying to base clinical decisions on scientific research yet still be able to offer his or her patients the latest materials and techniques. The key to the decision making process is a good understanding of the limitations and clinical indications of these newer materials as well as use of the correct techniques. Dentists should also keep basic biomechanical principles in mind and be wary of information put out by companies with a vested commercial influence.

\section{SUMMARY}

- Crowns on tooth preparations with margins beyond the CEJ and with adequate resistance form should be cemented in place with an rmgi cement rather than a resin cement. This then necessitates the use of a high strength, $\mathrm{Al}$ or $\mathrm{Zi}$ based ceramic system

- Crowns on tooth preparations with margins beyond the CEJ and with inadequate resistance form should be cemented in place with resin cements. Resin cements allow for either a low strength, glass based or high strength $\mathrm{Al}$ or $\mathrm{Zi}$ based system to be used assuming the underlying substrate is not too dark. Note that this is an unavoidable compromise because in order to achieve adequate retention, a resin cement needs to be used despite the fact that the margins are on dentine or cementum

- Crowns on tooth preparation with equigingival margins in enamel and good underlying substrate colour should be made from a translucent, glass based ceramic system. These will require cementation with a resin cement under rubber dam

- Crowns on a dark underlying tooth substrate need to be made from a high strength and opaque $\mathrm{Al}$ or $\mathrm{Zi}$ based ceramic system. For aesthetic reasons, the margins should be extended slightly subgingival beyond the CEJ. This will then necessitate cementation with an rmgi.

With thanks to Dennis Mostert of Ceramiart, London for the excellent technical work.

1. Douglas R D, Przybylska M. Predicting porcelain thickness required for dental shade matches. J Prosthet Dent 1999; 82: 143-149.

2. Andersson $M$, Carlsson $L$, Persson $M$, Bergman $B$. Accuracy of machine milling and spark erosion with a CAD/CAM system. J Prosthet Dent 1996; 76: 187-193.

3. Conrad H J, Seong W J, Pesun IJ. Current ceramic materials and systems with clinical recommendations: a systematic review. J Prosthet Dent 2007; 98: 389-404.

4. Raigrodski A J. All-ceramic full-coverage restorations: concepts and guidelines for material selection. Pract Proced Aesthet Dent 2005; 17: 249-256.

5. Marquardt P, Strub J R. Survival rates of IPS empress 2 all-ceramic crowns and fixed partial dentures: results of a 5 -year prospective clinical study. Quintessence Int 2006; 37: 253-259.

6. Fradeani M, Redemagni M. An 11-year clinical evaluation of leucite-reinforced glass-ceramic crowns: a retrospective study. Quintessence Int 2002; 33: 503-510.

7. Odman P, Andersson B. Procera AllCeram crowns followed for 5 to 10.5 years: a prospective clinical study. Int J Prosthodont 2001; 14: 504-509.

8. Fradeani M, D'Amelio M, Redemagni M, Corrado M. Five-year follow-up with Procera all-ceramic crowns. Quintessence Int 2005; 36: 105-113.

9. Heffernan M J, Aquilino S A, Diaz-Arnold A M 
Haselton D R et al. Relative translucency of six allceramic systems. Part I: core materials. J Prosthet Dent 2002; 88: 4-9.

10. Vichi A, Ferrari M, Davidson C L. Influence of ceramic and cement thickness on the masking of various types of opaque posts. J Prosthet Dent 2000; 83: 412-417.

11. Yoshida Y, Van Meerbeek B, Nakayama Y, Snauwaert J et al. Evidence of chemical bonding at biomaterial-hard tissue interfaces. J Dent Res 2000; 79: 709-714

12. Leevailoj C, Platt J A, Cochran M A, Moore B K. In vitro study of fracture incidence and compressive fracture load of all-ceramic crowns cemented with resin-modified glass ionomer and other luting agents. J Prosthet Dent 1998; 80: 699-707.

13. Snyder M D, Lang B R, Razzoog M E. The efficacy of luting all-ceramic crowns with resin-modified glass ionomer cement. J Am Dent Assoc 2003 May; 134: 609-612.

14. Blatz M B, Chiche G, Holst S, Sadan A. Influence of surface treatment and simulated aging on bond strengths of luting agents to zirconia. Quintessence Int 2007: 38: 745-753.

15. Coogan M M, Creaven P J. Antibacterial properties of eight dental cements. Int Endod J 1993; 26: 355-361.

16. Caputo A A, Standlee J P. In: Biomechanics in clinical dentistry. p 128. Chicago: Quintessence, 1997.

17. Trier A C, Parker M H, Cameron S M, Brousseau J S. Evaluation of resistance form of dislodged crowns and retainers. J Prosthet Dent 1998; 80: 405-409.

18. Goodacre C J. Tooth preparations for complete crowns: an art form based on scientific principles. J Prosthet Dent 2001; 85: 363-376.

19. Preston J D. Rational approach to tooth preparation for ceramo-metal restorations. Dent Clin North Am 1977; 21: 683-698.

20. Pashley D H. Clinical considerations of microleakage. J Endod 1990; 16: 70-77.

21. Gu XH, Kern M. Marginal discrepancies and leakage of all-ceramic crowns: influence of luting agents and aging conditions. Int J Prosthodont 2003; 16: 109-116.

22. Peumans $M$, Van Meerbeek $B$, Lambrechts $P$, Vanherle $G$. Porcelain veneers: a review of the literature. J Dent 2000; 28: 163-177.

23. Ibarra $G$, Johnson $G$ H, Geurtsen $W$, Vargas M A Microleakage of porcelain veneer restorations bonded to enamel and dentin with a new selfadhesive resin-based dental cement. Dent Mater 2007: 23: 218-225.

24. Lacy A M, Wada C, Du W, Watanabe L. In vitro microleakage at the gingival margin of porcelain and resin veneers. J Prosthet Dent 1992; 67: 7-10.

25. Sim C, Neo J, Chua E K, Tan B Y. The effect of dentine bonding agents on the microleakage of porcelain veneers. Dent Mater 1994; 10 : 278-281.

26. Tjan A H, Dunn J R, Sanderson I R. Microleakage patterns of porcelain and castable ceramic laminate veneers. J Prosthet Dent 1989; 61: 276-282.

27. Ferrari M, Mannocci F, Mason P N, Kugel G. In vitro leakage of resin-bonded all-porcelain crowns. J Adhes Dent 1999; 1: 233-242.

28. Burke F J T, Qualtrough A J E, Hale R W. Dentinebonded all-ceramic crowns: current status. JAm Dent Assoc 1998; 129: 455-460.

29. Yoo H M, Pereira P N. Effect of blood contamination with 1-step self-etching adhesives on microtensile bond strength to dentin. Oper Dent 2006: 31: 660-665.

30. Burke F J T, Qualtrough A J, Hale R W. The dentinebonded ceramic crown: an ideal restoration? Br Dent J 1995; 179: 58-63.

31. Burke FJ T. Four year performance of dentinebonded all-ceramic crowns. Br Dent J 2007: 202: 269-273.

32. de Munck J, van Meerbeek B, Yoshida Y, Inoue $S$ et al. Four-year water degradation of total-etch adhesives bonded to dentin. J Dent Res 2003; 82: $136-140$.

33. Materdomini $D$, Friedman M J. The contact lens effect: enhancing porcelain veneer esthetics. J Esthet Dent 1995; 7: 99-103. 